\title{
25
}

\section{PRME PARTNERS}

\section{From engagement to partnership}

\author{
Luisa Murphy and Nikolay Ivanov
}

In 2007, under the coordination of the UN Global Compact, 60 deans, official representatives of leading business schools, accreditation institutions, and student organizations worked closely as a taskforce to develop the Six Principles as a vehicle to transform management education. This multistakeholder effort led to the foundation of PRME.

Thirteen years later, some of these key partners continue to play a critical role in enabling PRME to achieve scale, relevance, and impact in the responsible management education field. As a partner-driven organization enabling and promoting the role of higher education in support of the SDGs, PRME depends on the inputs, inspiration, and commitment of its partners to advance its vision and mission. As outlined in SDG 17, partnerships are key levers for tackling systemic challenges and implementing the SDGs.

In this chapter, we discuss the context of PRME's engagement with partners and how PRME's collaborations enable the initiative to contribute to responsible management education (RME) and the SDGs. Finally, we share some ideas 
for accelerating the impact of PRME's partnerships in the future. In the spirit of partnership, we include partner voices as well as our own reflections on these topics. We appreciate previous and current partners for their support of PRME and welcome new partners to join PRME on its journey of transforming responsible management education and advancing the SDGs.

PRME defines partnerships as "a collaborative relationship among different organizations that work through advocacy, capacity building and collective action to inspire and accelerate collective, global, regional and local impact on responsible management education and the sustainable development goals (SDGs)."

\subsection{The context of PRME's engagement with partners}

Initially, PRME's engagement with partners mostly took place on a global scale. This is because of the central role that global business education networks (e.g., AACSB International, EFMD Global, AMBA), educational institutional partners (e.g., GRLI, ABIS), regional and specialized bodies (e.g., CEEMAN and CLADEA) and international student organizations (e.g., oikos International and Net Impact) played in the development of the Six PRME Principles and the initiative's strategic direction (See Chapter 5 on PRME's evolution for an overview of these developments). Since 2007, these partners have been playing a pivotal role in scaling up PRME's membership through the promotion of PRME and the Six Principles across their networks.

Today, PRME's ecosystem of diverse partners has evolved and grown as PRME pursues partnerships on global, regional, and local levels in order to achieve scale and impact toward its stated mission. PRME continues to engage with global partners including leading global business education networks, rankings, the media, academics and research networks, student organizations, companies, and members of the UN family to advance the PRME vision of creating a global movement and realizing the SDGs through responsible management education.

Student organizations spearhead the vision of PRME in business and management schools by actively promoting the Six Principles and the SDGs to their peers. As future business leaders, students challenge us to think differently by pushing the boundaries of the status quo and calling on their institutions to implement the Six Principles for responsible management education. 
Members of the UN family are also important partners. Since the inception of PRME, the UN Global Compact, as a "sister initiative," has been central to its development and administration, and continues to play a key role in supporting and advancing the PRME mission through the UN Global Compact network of over 10,000 companies (see Chapters 2 and 30 on PRME and the UN Global Compact). UNESCO is another PRME partner providing a strong mandate for PRME's vision and mission, as well as opportunities for engagement on both global and local levels.

PRME increasingly engages partners at the regional and local levels to accelerate the implementation of the Six Principles and its impact on the SDGs. Through its Regional Chapters, PRME seeks to foster regional and local partnerships that contextualize the Six Principles and the SDGs in different geographic, cultural, and linguistic contexts. Partnerships between the 16 PRME Regional Chapters and UN Global Compact Local Networks drive localized engagement for both higher education institutions and Global Compact companies on the regional and local levels in support of the SDGs (See Chapter 30 on UN Global Compact Networks and PRME for further examples). Such partnerships also enable PRME to scale up engagement within and between its Signatories in a specific geographic context.

\subsection{Impact of engagement on RME and the SDGs}

We asked partners how engagement between PRME and their organization has been advancing the RME agenda and the SDGs. According to partners, collaboration with PRME has contributed to advocacy, research, and capacity building in the RME field and on the SDGs.

\subsubsection{Advocacy and awareness on RME and the SDGs}

Engagement with partners has led to stronger advocacy and awareness of the importance of RME and the SDGs. For example, PRME's collaboration with leading media and ranking organizations has contributed to awareness on the increasing demand by students for new skills that equip them for the future of work. It has also made the public cognizant of the increasing demand by employers for employees with a sustainability mindset. These efforts have further reinforced the need for business and management schools to implement the Six Principles and to integrate the SDGs 
across curriculum, research and partnerships. They have also cast a light on leading business schools and best practices. ${ }^{1}$ Engagement with advocacy and awareness partners has been pivotal for shaping public opinion and providing a benchmark for how business schools can perform better creating a win-win for both PRME and its partners, ambitions in the context of RME and the SDGs. As one partner explains,

PRME has helped disseminate research ideas as the FT seeks to update its rankings to include more information and analysis on ESG and responsible business factors such as its current review on the FT50 and wider ways to measure academic research. The FT has featured and helped promote a debate on the key issues including articles referencing PRME.

Andrew Jack

In the context of the SDGs, collaboration between UNESCO and PRME has been crucial for advancing the UN Sustainable Development Agenda in higher education institutions and specifically, business and management schools. According to Ms. Stefania Giannini, Assistant Director-General for Education, UNESCO, and PRME Board Member,

The UN's 2030 Agenda is the most ambitious roadmap ever adopted to transform our world. The COVID-19 pandemic has only accelerated the urgency of a paradigm shift in our global development model to foster inclusion, shared innovations and sustainability. This calls first and foremost for leadership oriented towards gearing our economies and societies in this direction. Education is the starting point and springboard for this. UNESCO has collaborated with PRME over the years, going back to Rio +20 , where we launched the Higher Education for Sustainability Initiative.

\subsubsection{Research on RME and the SDGs}

In a similar vein, PRME's framework and focus on the SDGs complements partners efforts to produce robust, meaningful and impactful research on RME and SDG issues. As one partner explains,

PRME encourages business education to include learning about the SDGs and how to incorporate the SDGs into the strategic mission of business 
organizations. RRBM does not specify the specific topics of research but encourages more attention to the grand challenges or wicked problems of our world... PRME focuses on the "what" to study; RRBM...explains the "why" and defines the "how" of business research for generating both credible and useful knowledge that will contribute to a better world.

Anne Tsui

\subsubsection{Capacity building on RME and the SDGs}

Partners also view capacity building on RME and the SDGs as a key output resulting from their engagement with PRME. For example, the PRME Innovation Challenge (IC), created and led by the PRME Secretariat, brings together students from engaged PRME Signatories to work with companies to build sustainable business solutions addressing their SDG ambitions. This has provided training for students on sustainable solutions that they can apply to the business world (e.g., see Chapter 26 on PRME's Community Toolbox for examples of outputs resulting from collaborations). Collaboration between PRME and its partners clearly contributes to creating future business leaders that can offer companies expertise on the SDGs. According to one partner,

The PRME Innovation Challenge allows us to contribute to the sustainable development objectives set by the UN. The student perspective is interesting as it allows us to question ourselves. This is a generation that is particularly demanding with regard to sustainability challenges. They are responsible and they are the managers of tomorrow.

Michel Denis (Manitou, 2020 PRME Innovation Challenge Finale)

\subsection{From engagement to partnership}

Since its inception, engagement with partners has been guiding PRME in developing its vision and mission, and enabling a global movement for responsible management education. This is evidenced by PRME's network of $880+$ business and management school signatories and the impact PRME has had alongside our partners in relation to advocacy, research and capacity building in the RME field and more recently on the SDGs. 
Yet, as we reflect on engagement with partners over the last 13 years, we also see that there is potential for scaling up impact by placing greater emphasis on partnership for responsible management education and the SDGs. This implies a more active and strategic role for PRME in not only engaging with partners to scale up activities in support of its mission but also in fostering partnerships at the global, regional, and local levels to further accelerate impact, relevance and "systemic change" (Clarke \& Crane, 2018) in the RME field and on the SDGs.

In order to further accelerate its impact, PRME needs to reflect on the "collaborative potential" of key stakeholders to create internal value for the long-term sustainability of a particular partnership and to reflect on its "impact potential" to produce societal benefits (e.g., Vestergaard et al., 2021). As PRME expands its Signatory base and engagement into different corners of the world, it needs to consider how such partnerships, particularly in the Global South, impact intended beneficiaries as well as their role in empowering individuals (Vestergaard et al., 2019). While this will require greater capacity and resources, it would also lead to greater impact and transformational benefit to society (Austin \& Seitanidi, 2012).

One might ask, what type of impact can be expected from an enhanced focus on partnerships within the RME field and in relation to the SDGs in the future? Our conversations with partners suggest that a greater emphasis on partnership leads to four different types of value creation including business solutions and innovation for society, the necessary skills and mindset for the future, new norms on RME and positive societal impact as well as long-term policy change.

\subsubsection{Business solutions and innovation for society}

Partnerships can lead to a stronger focus on the SDGs at business and management schools and ultimately produce more sustainable solutions for global societal challenges. For example, partnerships between PRME and companies can lead to real business solutions. As one partner explains,

Of all the global programs that we support for education, we are particularly excited about PRME because it focuses on building and delivering real business solutions. In today's environment, students need more than 
just academic skills, they need the ability to innovate and collaborate and these are the skills that PRME is instilling in them.

Sujeet Chand (SVP Chief Technology Officer, Rockwell Automation, opening remarks at the 2020 PRME Innovation Challenge Finale)

Moreover, partnerships between PRME and research organizations can play an important role in providing solutions and "helping business schools to focus their research, of both the faculty and doctoral students on solving the economic, social and environmental challenges of our contemporary world" (Anne Tsui).

\subsubsection{Equipping leaders with the skills and mindset for the future}

Partnership has the capacity to equip future leaders with the skills and sustainability mindset needed for the future. One partner sums up this possibility with the following:

Looking into the future, we hope to continue fostering Responsible Management alongside PRME. Co-developing modules of questions has proved to be a fruitful experience, as it provides the students with the opportunity to engage with the topic actively. Instead of passively hearing or reading about it, taking the Sulitest prompts the test-takers to question their view and reflect upon their beliefs and awareness ... Sulitest would like to develop more modules of questions with PRME around various topics within RME, as well as engage with PRME members to further Education for Sustainable Development.

Sustainability Literacy Test (Sulitest)

\subsubsection{New norms on RME and positive societal impact}

Partnerships with organizations that promote norms on RME and the SDGs have an important role to play in incentivizing practices with positive societal impact. For example, PRME's partnership with media, ranking and accreditation organizations can create benchmarking, metrics, and best practices which ultimately lead to changing practices among business schools. One partner sums this up by explaining,

I see considerable potential in working with PRME as part of the FT's ongoing responsible business education initiatives to use both 
qualitative and quantitative approaches to identify, assess and showcase business schools' activities. This includes ways to identify a broader range of metrics and the development of common reporting standards for business schools such as how to measure academic research output and insights with societal impact, enhanced teaching, fostering of student-led initiatives and environmental reporting on campus activities. This would permit benchmarking, partnership, dissemination of best practice and incentivize more practices with positive societal impact in the future.

Andrew Jack

Another key driver of business schools' effort to develop and deliver high quality programs, research and educational frameworks in order to achieve positive societal impact are the global accreditation organizations. One strong example is evident in AACSB's new Business Accreditation Standards and particularly its Standard 9 focused on Engagement and Societal Impact referring to the role of business schools to make "a positive impact on the betterment of society, as identified in the school's mission and strategic plan."2 Moreover, looking closely at Standard 9, it becomes clear that PRME Signatories' SIP reports can be used as evidence of their efforts to make a positive impact on society. As noted by Timothy Mescon, Executive Vice President and Chief Officer - Europe, Middle East, and Africa at AACSB,

The collaboration between AACSB and PRME over the many years has been a true learning partnership. Today, I am delighted to see how we can both inspire and support business schools to improve and account for their social and societal engagement and impact all over the world. We have an exciting journey ahead of us and I have high aspirations for how AACSB and PRME may collaborate and support each other in the future.

Dan Le Clair, CEO of the Global Business School Network (GBSN), also explains the promise of GBSN's current partnership with PRME for collective action and scalable and systemic impact:

For any partnership, we ask what can be achieved together that cannot be achieved alone. The answer is clear for the GBSN and PRME Business and 
Human Rights Working Group initiative. We'll collaborate to convert the shared interests of leading faculty into collective action. Together we will link academia to practice, connect the Global South and North, co-create curriculum tools, and more.

\subsubsection{Policy change}

Partnership between PRME and UN and governmental actors has the potential to lead to long-term policy change on responsible management education and achievement of the SDGs. Stefania Giannini, Assistant Director-General for Education, UNESCO, highlights how partnership between PRME and UNESCO can create such impact.

As the only UN agency with a mandate in higher education, UNESCO sees business schools and universities as key actors in the "networked multilateralism" that is needed to advance sustainability and shared prosperity. PRME represents a prestigious and influential community that can catalyze transformation and advance regional and international collaboration around programmes that embed the Sustainable Development Goals. UNESCO's World Conferences coming up in 2021 on Education for Sustainable Development (Berlin, May) and Higher Education (Barcelona, October) are platforms for PRME to engage in promoting its principles and further developing alliances that put learning and leading for sustainability at the centre.

\subsection{Conclusion}

As a framework, the SDGs provide the most significant push for the global community to come together and adopt a plan for achieving a better future for all. SDG 17 calls for key stakeholders to forge collaborative partnerships in order to deliver on the SDGs and it has become ever so clear that higher education institutions have a crucial role to play in support of this process. Recognizing the interconnectedness and complexity of the SDGs, the PRME initiative is eager to scale up its engagement and impact across the wider community and thus partnering with and fostering partnerships among key stakeholders remains high on our agenda. 


\section{Notes}

1 For example, see FT's article on business schools shift: the https://www. ft.com/content/72do94ac-cf25-11e9-bo18-ca4456540ea6

2 See: https://www.aacsb.edu/-/media/aacsb/docs/accreditation/business/ standards-and-tables/2020\%20business \% 20 accreditation $\% 20$ standards.ashx?la =en\&hash $=\mathrm{E}_{4} \mathrm{~B} 7 \mathrm{D} 8348 \mathrm{~A} 686$ oB3AA9804567Fo2C6896 O281DA2

\section{References}

Austin, J.E., \& Seitanidi, M.M., (2012) 'Collaborative value creation: A review of partnering between nonprofits and businesses: Part I. Value creation spectrum and collaboration stages,' Nonprofit and Voluntary Sector Quarterly, 41(5), 726-758, DOI: 10.1177/0899764012450777

Clarke, A., \& Crane, A. (2018) 'Cross-sector partnerships for systemic change: Systematized literature review and agenda for further research,' Journal of Business Ethics, 150(2), 303-313, DOI: 10.1007/s10551-018-3922-2

Vestergaard, A., Langevang, T., Morsing, M., \& Murphy, L. (2O21) 'Partnerships for development: Assessing the impact potential of cross-sector partnerships,' World Development, 143, 105447. https://doi.org/10.1016/j. worlddev.2021.105447

Vestergaard, A., Murphy, L., Morsing, M., \& Langevang, T. (2019) 'Cross-sector partnerships as capitalism's new development agents: Reconceiving impact as empowerment,' Business Q Society, 59(7), 1339-1376, DOI: $10.1177 / 0007650319845327$ 